\title{
Anomalous iliac compliance in children with a single umbilical artery
}

\author{
C. L. Berry, R. G. Gosling, A. A. Laogun, and Elizabeth Bryan
}

From Department of Pathology and Physics, Guy's Hospital Medical School; and the Department of Paediatrics, University of Leeds

Arterial compliance (C) has been measured in 18 children known to have had a single umbilical artery at birth. Non-invasive ultrasonic Doppler techniques were used to measure $C$ for the aorta, iliac, and leg arteries. Anomalous compliance was found between the two iliac vessels, and it is suggested that this is the result of haemodynamic stress-induced changes during development. The demonstration that the form of large arteries may be changed by altered haemodynamic stress and that their physiological function is thus affected, may have important implications in the pathogenesis of degenerative disease.

In many organs and tissues, interference with growth at critical periods may affect their ultimate structure and function. Events of this type have been documented for the central nervous system (see Dobbing, 1974 for review), for the immunoreactive tissues (Smythe et al., 1971; Mathews et al., 1972) and the skeleton (Stewart et al., 1972), and for the fat organ (Brook, 1972). No such record has been made for the large arteries.

The elastic behaviour of the arterial wall at physiological pressures is almost entirely determined by the structure of the tunica media (Wolinsky and Glagov, 1964). Changes in the form of the media of large elastic arteries occur rapidly when the tension in the wall of the vessel is increased (Berry, 1969), and in the aorta chemical changes, notably a rapid increase in elastin content, occur soon after birth (Berry, Looker, and Germain, 1972). Certain aspects of aortic elastic function are known to change with age-for example, volume distensibility changes considerably in the first two decades of life (Gosling and King, 1975).

It is possible that changes in flow and pressure in large arteries during development affect the form of the media, and hence its functional characteristics. The studies of Bryan and Kohler (1974) on a large population of children identified (by examination of the umbilical cord) a number with unilateral absence of an umbilical artery. In these individuals the pattern of blood flow in the iliac vessels would be altered in intrauterine life. The Received 13 October 1975. study presented here was undertaken in order to explore the extent to which such departures from normal haemodynamic load might affect the medial structure in the iliac pathways.

It has only recently become practicable to measure vessel compliance in vivo by a noninvasive method using ultrasound, where the simultaneous use of two ultrasonic Doppler-shift blood velocimeters permits definition of a specific arterial pathway and allows determinations of compliance (Gosling and King, 1974). This method has been applied here.

\section{Subjects and methods}

Vessel compliance may be defined as $C=(\Delta D / D) / \Delta P$ ....(1), when $D$ is the lumen diameter at perfusion pressure $P$, and $\Delta D$ is the increase in diameter of the lumen produed by an increment $\Delta P$ in pressure. If we express the value of $C$ as 'per cent per $10 \mathrm{mmHg}$ $(13.3 \mathrm{kPa})$ pressure increment', this intrinsic wall property may be compared in subjects with differing pulse pressures.

Over a given vessel length, $L$, it is the average compliance of the vessel pathway that causes the delay or transit-time $(T)$ found between corresponding points of the proximal and distal pulse waves (of flow and/or pressure) observed for the same heart beat. The positions of the Doppler probes define the length of vessel pathway to be assessed (L). C is given by:

C per cent per $10 \mathrm{mmHg}(13.3 \mathrm{kPa})=0.667\left(\frac{\mathrm{T}}{\mathrm{L}}\right)^{2} \ldots$ 
taking average density of whole blood as $1.00, \mathrm{~T}$ in milliseconds and $\mathrm{L}$ in centimetres.

Eighteen children born with a single umbilical artery aged between 5 and 9 years were examined. Controls in this age range were taken from a study by Gosling and Laogun (1976) on the variation of arterial compliance with age in normal children. Each subject, controls and those with single umbilical artery, were rested, supine and horizontal, for at least 10 minutes before the examination began.

\section{Data collection}

Two $5 \mathrm{MHz}$ ultrasonic Doppler-shift blood velocimeters (Parks 701) were used in conjunction with a Sony stereo-tape recorder.

\section{Measurement of transit-time}

With subject supine and horizontal, Doppler detectors were placed on the skin successively in pairs over:

a) Left subclavian artery in the supraclavicular fossa and abdominal aorta just proximal to the aortic iliac bifurcation, i.e. over the aorta 0.1 to $0.2 \mathrm{~m}$ proximal to a line joining the iliac crests (aortic segment).

b) Aortic bifurcation (as defined above) and the left and right common femoral arteries in turn at the inguinal ligament (iliac segments).

c) Left common femoral site as above and the left posterior tibial artery (leg).

Probes were pointed towards the heart in all cases.

\section{Pressure}

Occlusion cuff pressures were taken in the right arm, the distal brachial artery being monitored with both stethoscope and Doppler detector independently.

\section{Data processing}

The Doppler-shift signals from the two detectors were recorded (at the sites above) and later analysed by a continuous two channel Spectrascribe (Coghlan, Taylor, and King, 1974). The sonagram traces of signals from the distal site are delayed compared with those from the proximal site, and this transit-time $T$ is measured from 'foot' to 'foot' of the sonagram waveforms (see Fig. 1). The resolution is limited by the ease of recognition of the foot. Using $5 \mathrm{MHz}$ carrier wave we can usually achieve a value correct to $\pm 4 \mathrm{~ms}$. Since perfusion pressure is respiration modulated, small changes in $T$ are found for successive heart beats. Thus observations were always made over several respiration cyclesusually 30 to 40 consecutive heart beats.

\section{Arterial pathway length}

The segment $L$ was in all cases a surface approximation. For site a) above, length was measured from the anterior midpoint of the sternal end of the clavicle to the position of the detector on the abdomen. For sites b) and c) distance was measured between detectors.

\section{Results}

\section{Subjects}

Table 1 A shows age, sex, height, weight, blood pressure (BP), mean arterial pressure $(\mathrm{P})$, and pulse pressure (P) of the 18 cases with single umbilical artery measured in this study. Table $1 \mathrm{~B}$
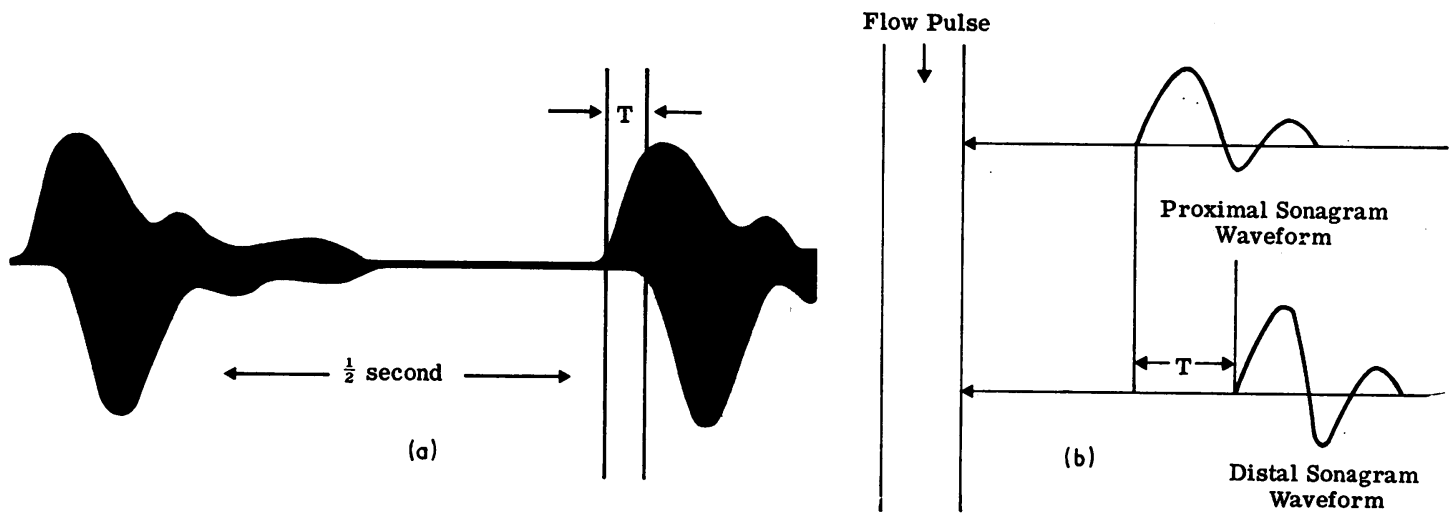

FIG. 1 Spectrascribe two-channel display of Doppler-signals from abdominal aorta and common femoral. Doppler frequency (proportional to red-cell velocity) 0 to $5 \mathrm{kHz}$ on $y$ axis, time on $x$ axis with blackness of trace proportional to number of red cells moving at any given velocity. Inverting distal trace allows easy and accurate measurement of foot to foot transit time, $T$, for any number of successive heart beats. Note well-defined maximum frequency outline or waveform of each sonagram. b) The foot-to-foot delay time $T$ between two sonagram waveforms measured simultaneously at different points known distance apart on blood vessel allows in vivo estimation of vessel compliance. 
TABLE 1A

\begin{tabular}{|c|c|c|c|c|c|c|c|}
\hline Case No. & $\begin{array}{l}\text { Age } \\
\text { (yr mth) }\end{array}$ & Sex & Weight (kg) & Height (m) & $B P(m m H g)$ & $\mathbf{P}$ & $\Delta P$ \\
\hline 1 & 7 & $\mathbf{F}$ & $23 \cdot 36$ & $1 \cdot 21$ & $108 \cdot 85$ & 93 & 23 \\
\hline 2 & 8 & F & 25.09 & $1 \cdot 27$ & $98 / 58$ & 81 & 40 \\
\hline 3 & 10 & $\mathbf{M}$ & 16.98 & $1 \cdot 18$ & $98 / 64$ & 75 & 34 \\
\hline 4 & 6 & $\mathbf{F}$ & $19 \cdot 73$ & $1 \cdot 13$ & $96 / 54$ & 68 & 42 \\
\hline 5 & 62 & $\mathbf{F}$ & $18 \cdot 37$ & $1 \cdot 16$ & $104 / 58$ & 73 & 46 \\
\hline 6 & 56 & $\mathbf{M}$ & $23 \cdot 33$ & $1 \cdot 15$ & $88 / 58$ & 68 & 30 \\
\hline 7 & 7 & $\mathbf{F}$ & $23 \cdot 13$ & $1 \cdot 15$ & $102 / 70$ & 81 & 32 \\
\hline 8 & 8 & $\mathbf{F}$ & $25 \cdot 4$ & 1.30 & $97 / 55$ & 69 & 42 \\
\hline 9 & 10 & $\mathbf{F}$ & 22.45 & 1.23 & $98 / 55$ & 69 & 43 \\
\hline 10 & 2 & $\mathbf{F}$ & $21 \cdot 32$ & $1 \cdot 19$ & $92 / 54$ & 67 & 38 \\
\hline 11 & 8 & $\mathbf{F}$ & 23.59 & $1 \cdot 26$ & $90 / 56$ & 71 & 44 \\
\hline 12 & 6 & $\mathbf{F}$ & 23.99 & $1 \cdot 18$ & $93 / 50$ & 72 & 43 \\
\hline 13 & 5 & $\mathbf{F}$ & $18 \cdot 37$ & 1.09 & $102 / 55$ & 71 & 47 \\
\hline 14 & 6 & $\mathbf{F}$ & $38 \cdot 1$ & 1.32 & $118 / 58$ & 78 & 59 \\
\hline 15 & 7 & $\mathbf{F}$ & $22 \cdot 68$ & $1 \cdot 19$ & $101 / 58$ & 72 & 43 \\
\hline 16 & 65 & $\mathbf{M}$ & 23.33 & $1 \cdot 23$ & $96 / 56$ & 69 & 40 \\
\hline 17 & 6 & $\mathbf{F}$ & $21 \cdot 32$ & $1 \cdot 13$ & $101 \cdot 58$ & 72 & 43 \\
\hline 18 & 5 & $\mathbf{M}$ & $17 \cdot 69$ & 1.05 & $108 \cdot 52$ & 71 & 56 \\
\hline
\end{tabular}

Conversion from Traditional Units to SI Units: $1 \mathrm{mmHg} \approx 0.133 \mathrm{kPa}$.

$\mathbf{P}$ Mean pressure. $\Delta \mathrm{P}$ Pulse pressure.

TABLE 1 B

\begin{tabular}{lllllll}
\hline $\begin{array}{l}\text { No. of normal } \\
\text { children }\end{array}$ & Age range $(y r)$ & $\begin{array}{l}\text { Average weight } \\
(\mathrm{kg})\end{array}$ & $\begin{array}{l}\text { Average height } \\
(\mathrm{m})\end{array}$ & $\begin{array}{l}\text { Average } \mathrm{BP} \\
(\mathrm{mmHg})\end{array}$ & Average $\mathrm{P}$ & Average $\Delta P$ \\
\hline 12 & $5-6$ & $20 \cdot 19$ & $1 \cdot 14$ & $89 / 56$ & 67 & 33 \\
25 & $6-7$ & $22 \cdot 54$ & $1 \cdot 19$ & $97 / 58$ & 71 & 39 \\
16 & $7-8$ & $25 \cdot 91$ & $1 \cdot 28$ & $101 / 59$ & 73 & 42 \\
19 & $8-9$ & $27 \cdot 16$ & $1 \cdot 32$ & $101 / 60$ & 74 & 41
\end{tabular}

Conversion from Traditional Units to SI Units: $1 \mathrm{mmHg} \approx 0.133 \mathrm{kPa}$.

$P$ Mean pressure.

$\Delta \mathbf{P}$ Pulse pressure.

shows the same values for normal children in the same age range as those with single umbilical artery.

\section{Compliance in normals: aortic, iliac, and leg segments}

The values of mean compliance $C$ with standard deviation found in the number of normal individuals shown in Table 1B for the various defined arterial pathways are set out in Table 2.

\section{Reproducibility of compliance values}

In October 1974 recordings were taken of Dopplershift signals and pathway lengths for the sites a), b), and c), as described in the method section, from the 18 subjects with single umbilical artery. Ten of these subjects were then re-examined in January 1975. Fig. 2 compares the values of compliance found on these two occasions for the aorta right, and left iliac pathways.
TABLE 2

\begin{tabular}{|c|c|c|c|c|}
\hline Age (yr) & 5 to 6 & 6 to 7 & 7 to 8 & 8 to 9 \\
\hline $\begin{array}{l}\text { No. of normal } \\
\text { children } \\
C+S D\end{array}$ & 12 & 25 & 16 & 19 \\
\hline Aorta & $\begin{array}{r}2.30 \\
\pm 0.19\end{array}$ & $\begin{array}{r}2.36 \\
+0.18\end{array}$ & $\begin{array}{r}2.50 \\
+0.20\end{array}$ & $\begin{array}{r}2.67 \\
\pm 0.16\end{array}$ \\
\hline Left iliac & $\begin{array}{r}2.03 \\
+0.20\end{array}$ & $\begin{array}{r}2.07 \\
+0.20\end{array}$ & $\begin{array}{r}2.11 \\
\pm 0.20\end{array}$ & $\begin{array}{r}2.14 \\
\pm 0.21\end{array}$ \\
\hline Right iliac & $\begin{array}{r}1.97 \\
\pm 0.17\end{array}$ & $\begin{array}{r}1.97 \\
+0.21\end{array}$ & $\begin{array}{r}2.12 \\
\pm 0.21\end{array}$ & $\begin{array}{r}2.10 \\
+0.18\end{array}$ \\
\hline Leg & $\begin{array}{r}1.34 \\
+0.16\end{array}$ & $\begin{array}{r}1.27 \\
+0.18\end{array}$ & $\begin{array}{r}1.14 \\
+0.16\end{array}$ & $\begin{array}{r}1.08 \\
+0.21\end{array}$ \\
\hline
\end{tabular}

\section{Compliance in cases with single umbilical artery: aorta, iliacs, and leg}

Fig. 3 shows the values of mean compliance as $\mathrm{C}$ per cent per $10 \mathrm{mmHg}(13.3 \mathrm{kPa})$, with standard deviation, and number of time delay $(T)$ observations, $\mathrm{N}$, for the aorta and left and right iliacs. The 


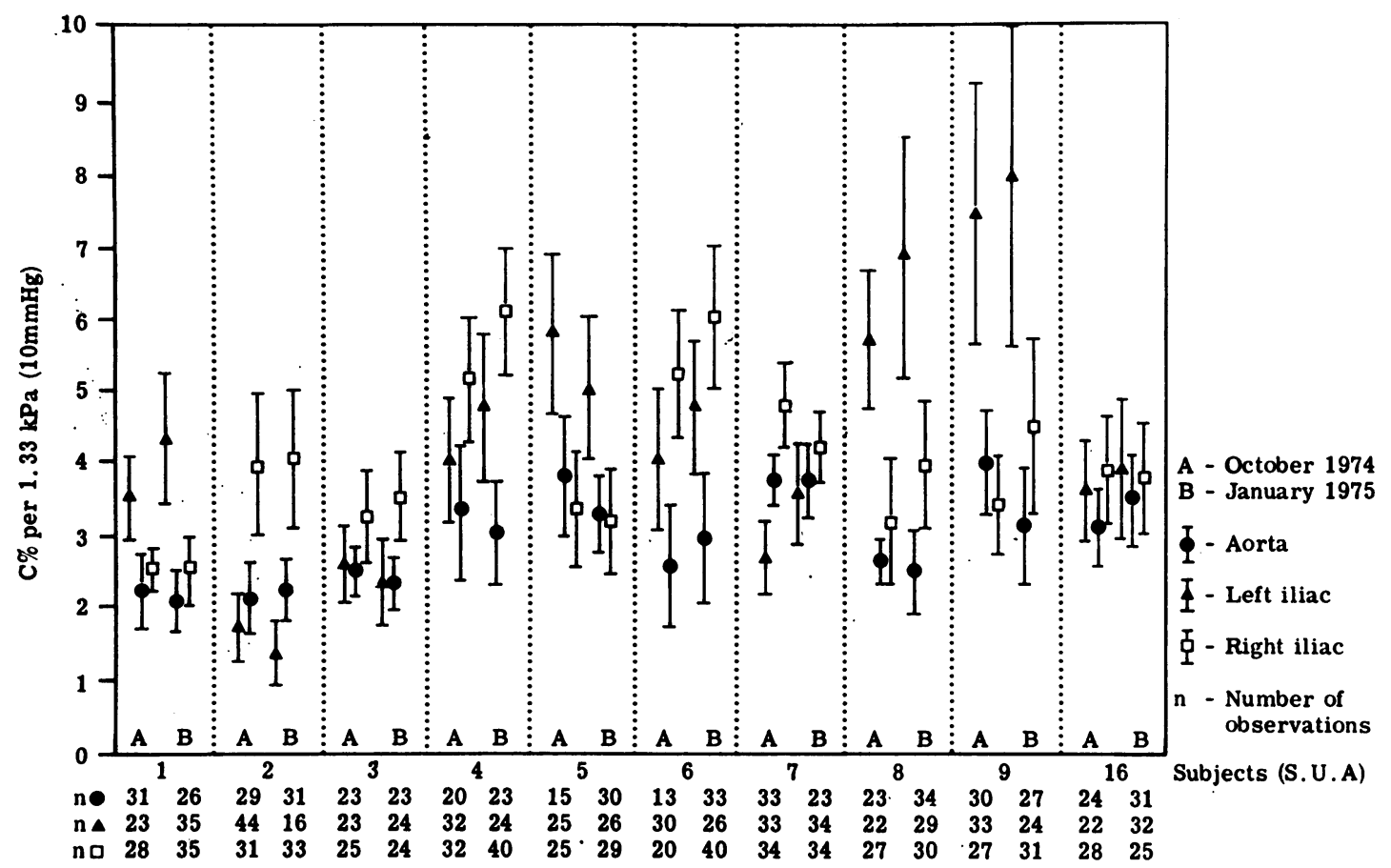

FIG. 2 Arterial compliance values for aorta, left, and right iliacs, of subjects with a single umbilical artery (S.U.A.) measured on two occasions about four months apart. Agreement of values shows reproducibility of method.

values are averaged measurements for the 10 subjects examined on visits $A$ and $B$ (shown in Fig. 2) and those of the remaining 8 subjects are calculated from readings taken at the first examination.

In all of the cases examined one iliac pathway was found to be more compliant than the other (left >right for 9 subjects and right $>$ left for 9 subjects). In Cases 1 to 15 this difference was statistically significant at better than the 99.9 per cent confidence level. In Cases 16 and 17, though the right iliac artery was more compliant than the left, the confidence level in these findings was low, e.g. Case 16: 0.02 $<\mathrm{P}<0.05$, Case 17: 0.2 $<\mathrm{P}<0.3$. However, in Case 16 the right iliac was significantly more compliant than the aorta $(P<0.001)$, and in Case 17 both iliacs were more compliant than the aorta at this level.

In 12 cases the most compliant iliac pathway was significantly more compliant than the aorta and in 5 cases both iliacs were more compliant than the aorta $(P<0.001)$. Only in Case 18 were iliac pathway compliance values not significantly higher than that of the aorta (L.I. $0.3<P<0.4$, R.I. $0.1<P<0.2$ ), though the right iliac was more compliant than the left with $0.001<P<0.01$.

Leg arteries showed no significant deviations between right or left or from normal values.

\section{Discussion}

A missing umbilical artery is associated with an increase in incidence of major malformation, prematurity and smallness for dates. This has been illustrated by Bryan and Kohler (1974) who found, in a survey of 20000 placentas, 143 with one artery instead of two. Of these 143 infants, 25 had major malformations, 20 being stillborn or dying in the first week of life; 33 were of low weight and 24 were preterm. It is from the group with no apparent malformations that the $\mathbf{1 8}$ children in this study were taken.

Follow-up studies on these children are in progress and have been reported elsewhere (Bryan and Kohler, 1974). In summary, there appears to be no readily observable characteristic that separates them from the general population. In particular, there is no evidence of leg shortening on either side, confirming the findings of Johnsonbaugh in 1973. In 8 infants known to have single umbilical artery 
who were examined in early life (up to 15 months), Johnsonbaugh commented that the results of transumbilical aortography in 5 infants showed the 'incidental finding of a markedly reduced caliber of common and of internal iliac arteries on the side where the umbilical artery was absent'.

Meyer and Lind (1974) have examined histologically the vessels of 8 infants with single umbilical artery between $2 \frac{1}{2}$ days and 4 years of age. They found that the common iliac artery on the side of the missing umbilical artery was small and muscular while that on the opposite side was enlarged, elastic in type, and showed pronounced calcification. Established atherosclerotic changes were also found in children of 18 months and 4 years of age.

In our study there is a striking increase in compliance in one iliac artery, which we have not found in controls. The aortic segment shows consistently higher compliance values than normals when means are compared. However, leg artery compliances do not differ significantly in the two groups. We suggest that haemodynamic stresses are responsible for all these findings, particularly those present on the side where the umbilical artery had existed in fetal life, and we suggest the following simple model; assume flow of blood to remain the same between fetus and placenta in normal subjects and those with single umbilical artery. The iliac artery from which the umbilical artery originates is now required to accommodate twice the volume flow. Since the flow is pulsatile this could be accomplished by doubling the volume strain $\Delta V / V$, i.e. doubling the compliance. From Fig. 3 it may be seen that in single umbilical artery (Cases 1 to 15) the most compliant iliac pathway has a compliance greater than the aorta by an average factor of 1.9 , whereas normal iliac compliance is found to be about the same or slightly less than the aorta (see above).

Persisting with this model, it may be shown that the compliance as defined in eq. 1 may be given by $C=(3 / 8) .(1 / E)(D / h)$

where $\mathrm{E}$ is the incremental modulus of the arterial wall, $D$ the average lumen diameter, and $h$ the wall thickness (Newman, Gosling, and Bowden, 1971). Thus we see that if the intrinsic elastic material of the artery wall does not change, i.e. $E$ remains the same, then observed results can be explained by doubling D/h. Recent studies (Berry, Greenwald,

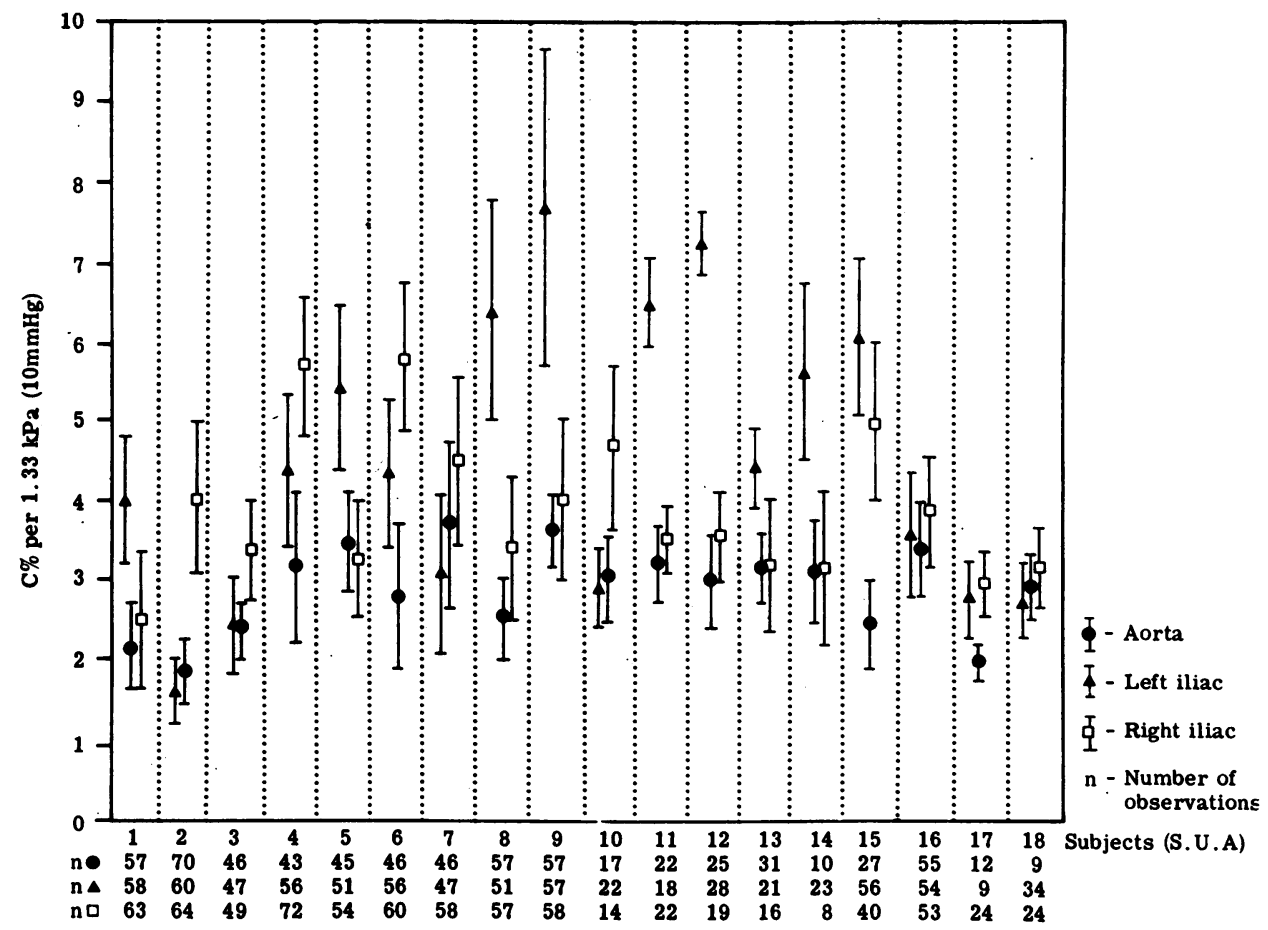

FIG. 3 Comparison of compliance of aortic and iliac pathways in 18 subjects with single umbilical artery (S.U.A.). 
and Rivett, 1975) have shown that in the rat $\mathrm{E}$ does not change as vessels grow and develop. It has also been suggested (Gosling and King, 1975) that in health changes in $E$ and $D / h$ invoked by normal physiology are such as to tend to minimize changes in compliance $\mathrm{C}$, and that one of the first steps in arterial disease is a significant departure of $C$ from 'in health values'.

We, therefore, conclude that the results presented here are consistent with the model suggested, i.e. that abnormal haemodynamic loading of the iliac pathway in utero is sufficient to change the value of $\mathrm{C}$ for the iliac pathway and to some extent the aorta. It is likely that the value of $\mathrm{D} / \mathrm{h}$ alters to produce most of the change with inevitable structural rearrangements of the media. This conclusion is supported by the findings of Meyer and Lind.

The demonstration that the form of large arteries may be changed by altered haemodynamic stress and that their physiological function is thus affected, may have important implications in the pathogenesis of degenerative disease.

Large elastic arteries continue to develop for the first two decades of life. Haemodynamic stresses may vary between individuals during this time; as Beresford and Holland (1973) have shown, children have blood pressure levels that relate to the levels of their parents by the age of 6 years. If such variability produces subtle arterial changes these may, in part, be responsible for variations in susceptibility to degenerative arterial disease.

\section{References}

Beresford, S. A. A., and Holland, W. W. (1973). Levels of blood pressure in children: a family study. Proceedings of the Royal Society of Medicine, 66, 1009.

Berry, C. L. (1969). Changes in the wall of the pulmonary artery after banding. Fournal of Pathology, 99, 29.

Berry, C. L., and Greenwald, S. E., and Rivett, J. F. (1975). Static mechanical properties of the developing and mature rat aorta. Cardiovascular Research, 9, 669.

Berry, C. L., Looker, T., and Germain, J. (1972). Nucleic acid and scleroprotein content of the developing human aorta. Fournal of Pathology, 108, 265.
Brook, C. G. D. (1972). Evidence for a sensitive period in adipose-cell replication in man. Lancet, 2, 624.

Bryan, E. M., and Kohler, H. G. (1974). The missing umbilical artery. 1: Prospective study based on a maternity unit. Archives of Disease in Childhood, 49, 844.

Coghlan, B. A., Taylor, M. G., and King, D. H. (1974). On-line display of Döppler shift spectra by a new time compression analyser. In Cardiovascular Applications of Ultrasound, p. 55. Ed. by R. S. Renemna. Worth-Holland, Amsterdam.

Dobbing, J. (1974). The later development of the brain and its vulnerability. In Scientific Foundation of Paediatrics, p. 565. Ed. by J. A. Davis and J. Dobbing. Heinemann, London.

Gosling, R. G., and King, D. H. (1974). Continuous wave ultrasound as an alternative and complement to $x$ ray in vascular examinations. In Cardiovascular Applications of Ultrasound, p. 266. Ed. by R. S. Reneman. North Holland, Amsterdam.

Gosling, R. G., and King, D. H. (1975). Ultrasonic angiology. In Arteries and Veins, p. 61. Eds A. W. Marcus and L. Adamson. Churchill Livingstone, Edinburgh.

Gosling, R. G., and Laogun, A. A. (1976). Compliance changes in health and disease. (in preparation).

Johnsonbaugh, R. E. (1973). Unilateral short lower extremity and single umbilical artery; absence of a relationship. American fournal of Diseases of Childhood, 126, 186.

Mathews, J. D., Whittingham, S., MacKay, I. R., and Malcolm, L. A. (1972). Protein supplementation and enhanced antibody-producing capacity in New Guinean school-children. Lancet, 2, 635.

Meyer, W. W., and Lind, J. (1974). Iliac arteries in children with a single umbilical artery. Structure, calcifications and early atherosclerotic lesions. Archives of Disease in Childhood, 49, 671 .

Newman, D. L., Gosling, R. G., and Bowden, N. L. R. (1971). Changes in aortic distensibility and area ratio with the development of atherosclerosis. Atherosclerosis, 14, 241.

Smythe, P. M., Schonland, M., Brereton-Stiles, G. G., Coovadia, H. M., Grace, H. J., Loening, W. E. K., Mafoyane, A., Parent, M. A., and Vos, G. H. (1971). Thymolymphatic deficiency and depression of cellmediated immunity in protein-calorie malnutrition. Lancet, 2, 939.

Stewart, R. J. C., Sheppard, H. G., Preece, R. F., and Exton-Smith, A. N. (1972). Bone resorption in the elderly. Age and Ageing, 1, 1.

Wolinsky, H., and Glagov, S. (1964). Structural basis for the static mechanical properties of the aortic media. Circulation Research, 14, 400.

Requests for reprints to Dr. C. L. Berry, Department of Pathology, Guy's Hospital Medical School, London SE1 9RT. 